\title{
Electrosensory pore distribution and feeding in the basking shark Cetorhinus maximus (Lamniformes: Cetorhinidae)
}

\author{
Ryan M. Kempster*, Shaun P. Collin \\ The UWA Oceans Institute and the School of Animal Biology, The University of Western Australia, 35 Stirling Highway, \\ Crawley, Western Australia 6009, Australia
}

\begin{abstract}
The basking shark Cetorhinus maximus is the second largest fish in the world, attaining lengths of up to $10 \mathrm{~m}$. Very little is known of its sensory biology, particularly in relation to its feeding behaviour. We describe the abundance and distribution of ampullary pores over the head and propose that both the spacing and orientation of electrosensory pores enables C. maximus to use passive electroreception to track the diel vertical migrations of zooplankton that enable the shark to meet the energetic costs of ram filter feeding.
\end{abstract}

KEY WORDS: Ampullae of Lorenzini · Electroreception · Filter feeding $\cdot$ Basking shark Resale or republication not permitted without written consent of the publisher

\section{INTRODUCTION}

Electroreception is an ancient sensory modality that has evolved independently across the animal kingdom in multiple groups (Scheich et al. 1986, Collin \& Whitehead 2004). Repeated independent evolution of electroreception emphasises the importance of this sense in a variety of aquatic environments, where electric fields produced by both living and inanimate sources are numerous (Collin \& Whitehead 2004). The electrosensory system of sharks is comprised of a series of electroreceptors, known as the ampullae of Lorenzini, distributed over almost the entire surface of the head anterior to the first gill slit. The major role of the ampullae of Lorenzini is thought to be for the detection of prey (Kalmijn 1971, Raschi et al. 2001, Kajiura et al. 2010). However, other functions have been suggested, including the detection of predators, the facilitation of social behaviours (Sisneros et al. 1998) and the ability to orientate to and navigate within the earth's magnetic field (Kalmijn 1974, 1978, 1982).

The basking shark Cetorhinus maximus is the second largest extant species of fish, attaining lengths of up to $10 \mathrm{~m}$ (Compagno 1984). These sharks inhabit temperate coastal waters worldwide and feed upon tiny zooplankton. C. maximus is 1 of only 3 extant filter-feeding sharks; the other 2 species are the whale shark Rhincodon typus and the megamouth shark Megachasma pelagios, which can attain lengths of up to 14 and $6 \mathrm{~m}$, respectively (Compagno 1984). These 3 filter-feeding sharks are among the largest living marine vertebrates (Compagno 1984) and yet they are all able to meet their energetic costs through the consumption of tiny zooplankton. $R$. typus and $M$. pelagios primarily utilise suction feeding, a strategy that allows them to draw high concentrations of zooplankton across their filter apparatus without the need for strong forward swimming speeds (Compagno 1990). C. maximus, on the other hand, capture zooplankton by filtering prey from the passive water flow over their gills using bristle-like rakers situated on the gill arches, a strategy known as ram filter feeding (Sims 2000). Therefore, regulation of efficient filtration of zooplankton relies heavily upon the ability of $C$. maximus to select appropriate swimming speeds so that the energetic reward exceeds, or at least meets, the energetic cost of ram filter feeding.

Filter-feeding sharks are faced with a unique problem for prey detection given the extremely heterogeneous distribution and abundance of zooplankton worldwide (Greene et al. 1998). Oceanic and innershelf fronts support high abundances of zooplankton and are known to be principal feeding areas for Cetorhinus maximus (Sims \& Quayle 1998). However, it is 
the response of these filter-feeding sharks to the vertical migrations of zooplankton that is relatively unknown. The daily change in vertical abundance of zooplankton, known as diel vertical migration (DVM), is a widespread behavioural phenomenon among marine and freshwater zooplankton species (Hays 2003) that influences foraging patterns of vertebrate predators (Sims et al. 2005). Zooplankton populations typically remain in deep water during the day, principally to avoid visually orientating predators (Bollens \& Frost 1989), and migrate to the surface at dusk to feed before returning to depth at dawn. Megachasma pelagios has been shown to exhibit DVM, which was previously thought to be a strategy to maintain a constant level of ambient light rather than to orient to higher zooplankton abundance (Nelson et al. 1997). However, if filterfeeding sharks use a DVM strategy based solely on light level, this may render them less able to respond to short- and long-term changes in the vertical distribution of zooplankton (Sims \& Quayle 1998). Fortunately, sharks have an advantage over most other marine predators, as they possess the ability to orient towards the bioelectric fields of their prey (Kalmijn 1974). Passive electroreception has been identified as a possible mechanism for $M$. pelagios to orientate towards and follow zooplankton populations through their DVM (Kempster \& Collin 2011), negating the need to follow ambient light cues, as previously suggested (Nelson et al. 1997). In the present paper we describe the abundance and distribution of ampullary pores on a C. maximus specimen and discuss how this may enable the shark to track the DVM of zooplankton.

\section{MATERIALS AND METHODS}

A specimen of Cetorhinus maximus was obtained from the elasmobranch collection at the Museum of Western Australia. The specimen of $\sim 325 \mathrm{~cm}$ in length was collected off the coast of Busselton, Western Australia, in 1969 and has been preserved in $70 \%$ ethanol for $42 \mathrm{yr}$. Although it was apparent that some degree of tissue shrinkage had occurred, the ampullary pores were still clear and easily distinguishable from the lateral line pores. Given the rarity of this species worldwide and that this was the only specimen of its kind in this collection, no dissection of the ampullary pores was permitted, negating any chance of histological analysis. Pores were counted in situ using transparencies that were laid over the surface of the head, on to which the position of individual pores were marked. Multiple photographs were taken of the head and relative pore region positions, which were later used to assist in producing the pore map presented here, with the aid of a CorelDRAW ${ }^{\circledR}$ graphics suite (see Fig. 1).

\section{RESULTS}

A total of 301 ampullary pores were present on the head of Cetorhinus maximus, with all pores located on the protruding snout, anterior to the upper jaw margin (Fig. 1). Most pores were located on the lateral (L, $59 \%$ ) and dorsal (D, 35\%) surfaces of the head, with very few on the ventral surface $(\mathrm{V}, 6 \%$; Table 1$)$. Ampullary pores were found in the greatest numbers parallel (1D left and 1D right) and anterior (1L left and 1L right) to the eyes on the dorsal and lateral surfaces, with these fields each containing between 52 and 68 pores (Table 1, Fig. 1). Pores located towards the anterior edge of the snout (1L left and $1 \mathrm{~L}$ right) are spread across a narrow strip that widens towards the posterior margin to surround the anterior edge of the nares (Fig. 1). Posterior to each naris is a small region of pores (2L left and $2 \mathrm{~L}$ right) located in front of the eye that may in fact be a continuation of the pore regions anterior to each nare (1L left and 1L right). For the purposes of the present investigation these regions (1L left and $1 \mathrm{~L}$ right; $2 \mathrm{~L}$ left and $2 \mathrm{~L}$ right) have been split to allow a better interpretation of pore distribution. Regions with the lowest pore abundance (3L left and $3 \mathrm{~L}$ right; $1 \mathrm{~V}$ left and $1 \mathrm{~V}$ right) were found posterior to the nares, between the eye and upper jaw margin, and did not extend much further back than 1 eye length from the posterior margin of the eye (Table 1, Fig. 1).

\section{DISCUSSION}

Cetorhinus maximus is the only shark species currently described with no electrosensory pores on the lower jaw, in the mandibular pore region (Fig. 1). This region of the head in sharks is generally characterised by low pore abundance and is thought to assist in guiding the mouth towards suitable prey during the final phase(s) of the feeding strike (Chu \& Wen 1979, Cornett 2006). The unique morphology of the mouth and the fact that $C$. maximus is a ram filter feeder would negate any need for mandibular pores. The large gape created between the mandibular pore region and the anterior pore regions of the snout during ram filter feeding can be as much as $1 \mathrm{~m}$ (Matthews \& Parker 1950) and would render mandibular pores ineffective; C. maximus would not be able to determine a relative prey concentration throughout this space, given the weak bioelectric fields of zooplankton and the effective range of the ampullae of Lorenzini being only $\sim 30 \mathrm{~cm}$ (Kajiura \& Holland 2002).

All organisms produce bioelectric fields, which in zooplankton can be up to $1 \mathrm{mV} \mathrm{cm}^{-1}$, and species such as the paddlefish have been shown to actively hunt for zooplankton using passive electroreception (Wojtenek 

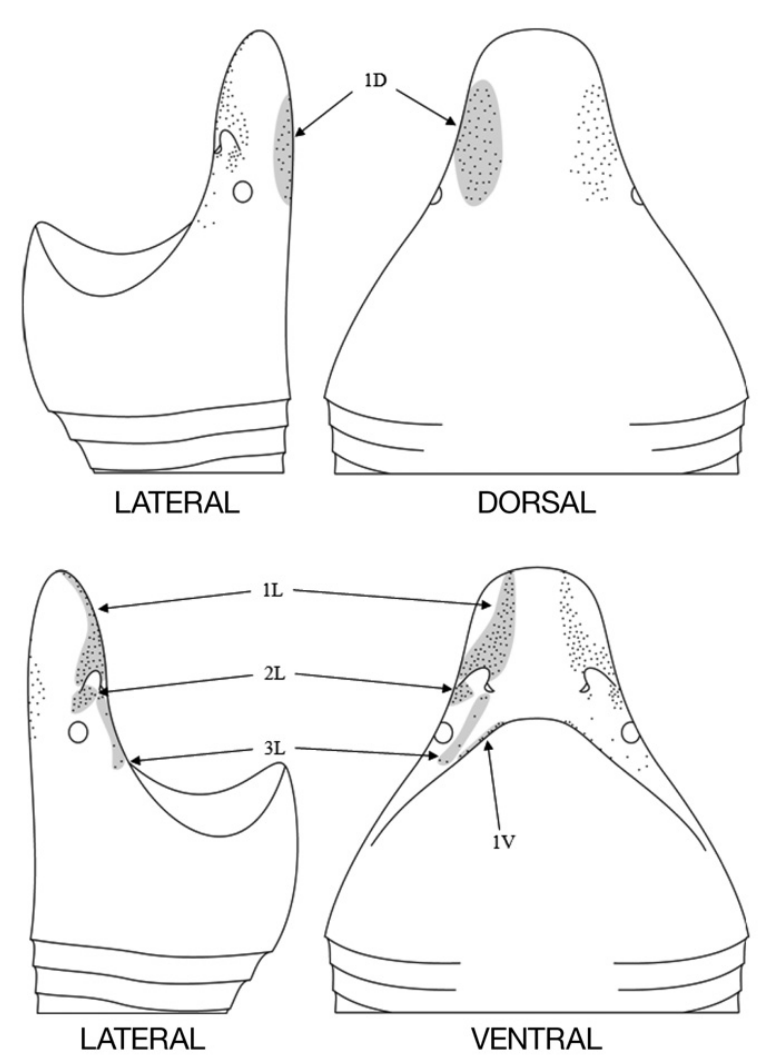

Fig. 1. Cetorhinus maximus. Electrosensory pore distribution map. D: dorsal; L: laterali V: ventral

Table 1. Cetorhinus maximus. Morphometric data for the basking shark specimen. Ampullary pore abundance on the ventral (V), dorsal (D) and lateral (L) surfaces, and in total

\begin{tabular}{|lc|}
\hline N & 1 \\
Sex & Unknown \\
Total length $(\mathrm{cm})$ & 325 \\
No. of ventral pores & 17 \\
1V left & 9 \\
1V right & 8 \\
No. of dorsal pores & 106 \\
1D left & 52 \\
1D right & 54 \\
No. of lateral pores & 178 \\
1L left & 66 \\
1L right & 68 \\
2L left & 15 \\
2L right & 15 \\
3L left & 8 \\
3L right & 6 \\
Total no. of pores & 301 \\
\hline
\end{tabular}

et al. 2001). Sharks have been shown to detect electric

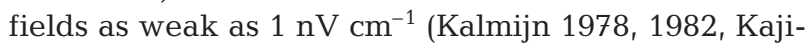
ura \& Holland 2002). It is therefore possible that Cetorhinus maximus may use passive electroreception to determine the presence, and to some degree the abundance, of planktonic prey around its head, as we earlier proposed for Megachasma pelagios (Kempster \&
Collin 2011). However, unlike $M$. pelagios, the snout of C. maximus protrudes anteriorly in front of the mouth, and is covered in electrosensory pores (Fig. 1); the snout may act as an electrosensitive probe to guide the mouth of $C$. maximus towards dense zooplankton assemblages to increase ram filter-feeding efficiency. The arrangement of electrosensory pores around almost the whole snout (Table 1, Fig. 1) of C. maximus may allow the shark to identify changes in the vertical and horizontal abundance of zooplankton. This is further supported by a decrease in swimming speed during filter feeding (Sims 2000) that may provide the conditions necessary to establish the spatial distribution of zooplankton around the snout. This would enable $C$. maximus to follow higher concentrations of zooplankton populations throughout their DVM, and thus maintain efficient filtration of zooplankton to meet the energetic costs of ram filter feeding.

All 3 extant filter-feeding shark species have independently evolved unique feeding behaviours (Wilga et al. 2007), yet similarities in the electrosensory pore abundance of at least Cetorhinus maximus and Megachasma pelagios (Table 2) suggest that their electrosensory systems have concomitantly evolved a similar sampling strategy for the detection of bioelectric fields of near-field prey items. The closest living relatives of C. maximus and M. pelagios, but still classified within the order Lamniformes, show a large range of electrosensory pore abundance, in the order of 2 to 7 times greater than $C$. maximus and $M$. pelagios (Table 2). These unique differences in pore abundance have been attributed to habitat-specific conditions and species-specific differences in feeding strategy (Raschi et al. 2001, Cornett 2006). C. maximus and $M$. pelagios exhibit the lowest electrosensory pore abundances of the lamniform sharks (Table 2) and also some of the lowest pore abundances of any shark species examined to date (Chu \& Wen 1979, Cornett 2006, Kajiura et al. 2010), highlighting the significance of passive electroreception in relation to their specific lifestyle and feeding mechanisms.

To further understand and confirm the potentially significant role that electroreception plays in the filterfeeding behaviour of sharks, data must be obtained for the only other filter-feeding shark, the whale shark Rhincodon typus. However, to truly appreciate how the electroreceptive systems of filter-feeding sharks relate to feeding behaviour, a complete histological analysis of electroreceptors is needed.

Acknowledgements. The authors thank the Endeavour Foundation, University of Western Australia and the Western Australia State Government for funding this work and S. Morrison from the Museum of Western Australia for her continued support and help in gaining access to specimens. Our sincere thanks to C. Egeberg and C. Kerr for their invaluable logistics support throughout this work. 
Table 2. Ampullae of Lorenzini pore abundance for species of the order Lamniformes. No data available for Mitsukurinidae family

\begin{tabular}{|llcl|}
\hline Lamniform family & Species (no. of replicates) & Total no. of pores ${ }^{\mathrm{a}}$ & Source \\
\hline Alopiidae & Alopias pelagicus (2) & 1483 & Cornett (2006) \\
& A. superciliosus (1) & 1338 & Cornett (2006) \\
Pseudocarcharhiidae & Pseudocarcharias kamoharai (1) & 1152 & Cornett (2006) \\
Odontaspididae & Carcharias taurus (1) & 1130 & Cornett (2006) \\
& Carcharias taurus (2) & 1030 & Raschi et al. (2001) \\
Lamnidae & Isurus paucus (1) & 774 & Cornett (2006) \\
& Lamna nasus (2) & 736 & Raschi et al. (2001) \\
& I. oxyrinchus (6) & $7001)$ \\
Cetorhinidae & I. oxyrinchus (1) & 635 & Cornett (2006) \\
Megachasmidae & L. ditropis (1) & 444 & Present study \\
Cetorhinus maximus (1) & 301 & Kempster \& Collin (2011) \\
\end{tabular}

\section{LITERATURE CITED}

Bollens SM, Frost BW (1989) Predator-induced diel vertical migration in a planktonic copepod. J Plankton Res 11: 1047-1065

Chu Y, Wen M (1979) Monograph of fishes of China (No. 2): a study of the lateral-line canals system and that of Lorenzini ampullae and tubules of elasmobranchiate fishes of China. Science and Technology Press, Shanghai

Collin SP, Whitehead D (2004) The functional roles of passive electroreception in non-electric fishes. Anim Biol $54: 1-25$

Compagno L (1984) FAO species catalogue, Vol 4. Sharks of the world. An annotated and illustrated catalogue of shark species known to date. Part 1. Hexanchiformes to Lamniformes. FAO Fish Synop 125:1

Compagno L (1990) Relationships of the megamouth shark, Megachasma pelagios (Lamniformes, Megachasmidae), with comments on its feeding habits. NOAA Tech Rep 90: $357-379$

Cornett A (2006) Ecomorphology of shark electroreceptors. MS thesis, Florida Atlantic University, Boca Raton, FL

Greene CH, Wiebe PH, Pershing AJ, Gal G and others (1998) Assessing the distribution and abundance of zooplankton: a comparison of acoustic and net-sampling methods with D-BAD MOCNESS. Deep-Sea Res II 45:1219-1237

$>$ Hays GC (2003) A review of the adaptive significance and ecosystem consequences of zooplankton diel vertical migrations. Hydrobiologia 503:163-170

Kajiura S, Holland K (2002) Electroreception in juvenile scalloped hammerhead and sandbar sharks. J Exp Biol 205: 3609-3621

Kajiura S, Cornett A, Yopak C (2010) Sensory adaptations to the environment: electroreceptors as a case study. In: Carrier JC, Musick JA, Heithaus MR (eds) Sharks and their relatives. II. Biodiversity, adaptive physiology, and conservation. CRC Press, Boca Raton, FL, p 393-429

Kalmijn AJ (1971) The electric sense of sharks and rays. J Exp Biol 55:371-383

Kalmijn AJ (1974) The detection of electric fields from inanimate and animate sources other than electric organs. In: Fessard A (ed) Handbook of sensory physiology, Vol III/3. Springer-Verlag, Berlin, p 147-200
Kalmijn AJ (1978) Electric and magnetic sensory world of sharks, skates and rays. In: Hodgson ES, Mathewson RF (eds) Sensory biology of sharks, skates and rays. Office of Naval Research, Arlington, VA, p 507-528

Kalmijn AJ (1982) Electric and magnetic field detection in elasmobranch fishes. Science 218:916-918

Kempster RM, Collin SP (2011) Electrosensory pore distribution and feeding in the megamouth shark Megachasma pelagios (Lamniformes: Megachasmidae). Aquat Biol 11: $225-228$

Matthews LH, Parker HW (1950) Notes on the anatomy and biology of the Basking Shark (Cetorhinus maximus (Gunner)). Proc Zool Soc Lond 120:535-576

Nelson DR, McKibben JN, Strong WR, Lowe CG, Sisneros JA, Schroeder DM, Lavenberg RJ (1997) An acoustic tracking of a megamouth shark, Megachasma pelagios: a crepuscular vertical migrator. Environ Biol Fishes 49:389-399

Raschi W, Aadlond C, Keithar ED (2001) A morphological and functional analysis of the ampullae of Lorenzini in selected galeoid sharks. In: Kapoor BG, Hara TJ (eds) Sensory biology of jawed fishes. Science Publishers, Enfield, NH, p 297-316

Scheich H, Langner G, Tidemann C, Coles RB, Guppy A (1986) Electroreception and electrolocation in platypus. Nature 319:401-402

Sims DW (2000) Filter-feeding and cruising swimming speeds of basking sharks compared with optimal models: they filter-feed slower than predicted for their size. J Exp Mar Biol Ecol 249:65-76

Sims DW, Quayle VA (1998) Selective foraging behaviour of basking sharks on zooplankton in a small-scale front. Nature 393:460-464

Sims DW, Southall EJ, Tarling GA, Metcalfe JD (2005) Habitatspecific normal and reverse diel vertical migration in the plankton-feeding basking shark. J Anim Ecol 74:755-761

Sisneros JA, Tricas TC, Luer CA (1998) Response properties and biological function of the skate electrosensory system during ontogeny. J Comp Physiol A 183:87-99

Wilga CD, Motta PJ, Sanford CP (2007) Evolution and ecology of feeding in elasmobranchs. Integr Comp Biol 47:55-69

- Wojtenek W, Pei X, Wilkens L (2001) Paddlefish strike at artificial dipoles simulating the weak electric fields of planktonic prey. J Exp Biol 204:1391-1399 